\title{
Echolocation and distribution of Saccolaimus saccolaimus in north-western Australia
}

\author{
N.L. McKenzie 1, ${ }^{1,}$ R.D. Bullen², M.A. Cowan ${ }^{1}$ and D.J. Milne ${ }^{3}$ \\ ${ }^{1}$ Woodvale Research Centre, Department of Biodiversity Conservation and Attractions, Wildife \\ Place, Woodvale, Western Australia 6026, Australia. \\ 243 Murray Drive, Hillarys, Western Australia 6025, Australia. \\ ${ }^{3}$ Department of Environment and Natural Resources, PO Box 496, Palmerston, Northern Territory \\ 0831, Australia. \\ * Corresponding author: norman.mckenzie1@gmail.com
}

\begin{abstract}
Specimens of the vulnerable bat Saccolaimus saccolaimus have recently been recognised among museum collections from north-western Australia. They include one whose search mode echolocation pulses were being recorded when it was collected. In terms of spectral characters, this pulse sequence was indistinguishable from reference sequences by $S$. saccolaimus from the Northern Territory.

We compare these reference sequences with free-flying sequences: (1) from the two other species at the same detection sites that have a similar acoustic niche (Saccolaimus flaviventris and Chaerephon jobensis), and (2) recorded from sites elsewhere in north-western Australia. Equivalent sequences were detected at 40 of 173 recording sites scattered throughout north-western Australia, and in all five of its bioregions, implying that $S$. saccolaimus is widespread at the western end of its geographical range in Australia. At an overall average frequency of $20.3 \mathrm{kHz}$, these sequences, like their Northern Territory counterparts, are significantly different from S. flaviventris and C. jobensis in all spectral parameters measured, and consistent with (albeit $2.8 \mathrm{kHz}$ lower than) $S$. saccolaimus sequences from Queensland.
\end{abstract}

KEYWORDS: Kimberley, bats, museum collections, vulnerable species, Northern Territory, Queensland

\section{INTRODUCTION}

The vulnerable bat Saccolaimus saccolaimus (Temminck, 1838) is known in Australia from the high rainfall tropical regions of Northern Territory and Queensland (T.S.S.C. 2016), but data on its range limits and habitat associations are scant because there are few museum specimens and known localities. As Woinarski et al. (2014) pointed out, field surveys have been hampered by difficulties in diagnosing its echolocation sequences from those of co-occurring species such as Saccolaimus flaviventris (Peters, 1867) and C. jobensis (Miller, 1902). Historically, all Western Australian Saccolaimus have been identified as S. flaviventris because they lack the bare rump and/or numerous dorsal flecks, speckles or spots that characterise Queensland S. saccolaimus.

Two recent events prompted a reevaluation of these identifications. Firstly, a mitochondrial DNA study of specimens from Queensland and Northern Territory revealed that, although $S$. saccolaimus forms a single genetic clade in Australia, a proportion of the Northern Territory S. saccolaimus population lacks the bare rump and/or dorsal markings (Milne et al. 2009). It also showed that adults have a narrower 'outer-upper canine width' $\left(\mathrm{OC}^{1} \mathrm{~W}<5.7 \mathrm{~mm}\right.$ ) than $S$. flaviventris. Using this metric, specimens from five localities in the Kimberley, north-western Australia, were subsequently discovered in the Western Australian Museum (WAM) collection (see Woinarski et al. 2014): WAM M21831, M24019, M26078, M49194 and M64808 (Table 1). They did not have the distinctive bare rump, white dorsal flecks/ speckles/spots, dark reddish-brown dorsal fur or pale brown to grey ventral fur of most individuals belonging to Queensland populations. Instead, they had uniform dark brown to black dorsal fur and creamy-white ventral fur just like Saccolaimus flaviventris, the only congeneric known from the Kimberley.

Secondly, during an acoustic survey of bats on islands along the Kimberley coast, we noticed that search mode echolocation sequences we were assigning to 
$S$. flaviventris formed two discrete clusters in terms of spectral parameters. Subsequent study revealed that one of these clusters resembled S. saccolaimus sequences from the Northern Territory, illustrated in Milne et al. (2009). Fortuitously, the echolocation sequence emitted by one of the vouchered $S$. saccolaimus specimens was being recorded when it was shot (flying through the beam of a spotlight), thus providing a reference sequence from the Kimberley.

In this study we document the echolocation signature of S. saccolaimus and reassess its geographic range in the Kimberley, where it was virtually unknown. We provide comparison with free-flying reference echolocation sequences by its two acoustic neighbours (S. flaviventris and C. jobensis) to facilitate future surveys. Specifically, we assess the hypothesis that S. saccolaimus occurs throughout the Kimberley by (a) reappraising the Saccolaimus collections in the Western Australian Museum for adult specimens with 'outerupper canine width' $<5.7 \mathrm{~mm}$, and (b) by searching our library of ultrasound recordings from the Kimberley for echolocation sequences that match the $S$. saccolaimus reference sequences from the Northern Territory and/or the Kimberley reference sequence. Animal Ethics Committee approvals: A02001 (NT) and DEC 2010/21 (WA).

\section{MATERIALS AND METHODS}

\section{STUDY AREA}

The Kimberley Administrative Region occupies north-western Australia and, for brevity, is referred to as the 'Kimberley' in this paper. Sparsely settled and with limited access, it spans $600 \mathrm{~km}$ north-to-south and $800 \mathrm{~km}$ east-to-west, includes both coastal and inland landscapes, and has a hot tropical climate. It is divided into five geomorphically distinctive bioregions (DSEWPaC 2012), see Figure 1. The Northern and Central Kimberley bioregions comprise rugged uplands of the Kimberley Craton; the other three are

TABLE 1 Adult S. saccolaimus specimens from Kimberley locations (WAM\# = Western Australian Museum specimen registration number).

a Scaled from forearm length of the other female specimens.

b Scaled from dried alcohol specimen using specimens of known fresh weight.

\begin{tabular}{|c|c|c|c|c|c|c|}
\hline $\begin{array}{l}\text { Site } \\
\text { (Figure 1) }\end{array}$ & WAM\# & Sex & Location (WMG) & $\begin{array}{l}\text { Radius, } \mathrm{D}^{3} \mathrm{P}^{1} \\
\mathrm{OC}{ }^{1} \mathrm{~W}(\mathrm{~mm})\end{array}$ & Weight (g) & Notes \\
\hline 10 & M21831 & q & $\begin{array}{l}\text { Mitchell Plateau at } \\
14^{\circ} 49^{\prime} 16^{\prime \prime} \mathrm{S} \\
125^{\circ} 50^{\prime} 34^{\prime \prime} \mathrm{E}\end{array}$ & $73.4,31.1,5.6$ & & WAM/CRA on 25 April 1982 \\
\hline 18 & M49194 & $\hat{0}$ & $\begin{array}{l}\text { Mitchell River track at } \\
15^{\circ} 08^{\prime} 45^{\prime \prime} \mathrm{S} \\
126^{\circ} 09^{\prime} 30^{\prime \prime} \mathrm{E}\end{array}$ & $73.3,31.9,5.7$ & 38.2 & $\begin{array}{l}\text { Shot well above riparian canopy } \\
\text { by N. McKenzie and J. Rolfe } \\
\text { on } 2 \text { June } 1987\end{array}$ \\
\hline 128 & M24045 & 우 & $\begin{array}{l}\text { Tunnel Creek, } \\
\text { near Fairfield HS. } \\
17^{\circ} 36^{\prime} 26^{\prime \prime} \mathrm{S}, \\
125^{\circ} 08^{\prime} 44^{\prime \prime} \mathrm{E}\end{array}$ & $75.0,30.8,5.4$ & $40.5^{\mathrm{a}}$ & $\begin{array}{l}\text { G. Barron \& P. Griffin on } \\
\text { 4 February } 1982\end{array}$ \\
\hline 152 & M24019 & $\hat{0}$ & $\begin{array}{l}\text { Barred Creek Bore. } \\
17^{\circ} 39^{\prime} 45^{\prime \prime} \mathrm{S} \\
122^{\circ} 12^{\prime} 10^{\prime \prime} \mathrm{E}\end{array}$ & $70.5,30.9,5.6$ & & $\begin{array}{l}\text { Shot above pindan canopy by } \\
\text { G. Barron and P. Griffin on } \\
24 \text { January } 1982\end{array}$ \\
\hline A & M26078 & $\widehat{0}$ & $\begin{array}{l}\text { Sale River at } \\
16^{\circ} 01^{\prime} 37^{\prime \prime S} \\
124^{\circ} 45^{\prime} 52^{\prime \prime} \mathrm{E}\end{array}$ & $71.2,30.5,5.6$ & 39.1 & $\begin{array}{l}\text { Shot in open air above riparian } \\
\text { canopy by K.F. Kenneally on } \\
13 \text { May } 1986\end{array}$ \\
\hline B & M64808 & q & $\begin{array}{l}\text { Kimbolton HS. } \\
16^{\circ} 41^{\prime} 00^{\prime \prime} \mathrm{S} \\
123^{\circ} 50^{\prime} 00^{\prime \prime} \mathrm{E}\end{array}$ & $73.3,31.1,5.5$ & $40.8^{\mathrm{b}}$ & K. Goodchild in 2006 \\
\hline $\mathrm{C}$ & M22535 & q & $\begin{array}{l}\text { Coulomb Point. } \\
17^{\circ} 20^{\prime} 10^{\prime \prime} \mathrm{S} \\
122^{\circ} 09^{\prime} 40^{\prime \prime} \mathrm{E}\end{array}$ & $--, 33.3,5.7$ & 45.0 & $\begin{array}{l}\text { Shot } 15 \mathrm{~m} \text { above shrubland on } \\
\text { beach dune by N. McKenzie on } \\
19 \text { April } 1987\end{array}$ \\
\hline $\mathrm{D}$ & M44078 & - & $\begin{array}{l}\text { Osmond Range } \\
17^{\circ} 16^{\prime} 35^{\prime \prime} \mathrm{S} \\
128^{\circ} 15^{\prime} 30^{\prime \prime} \mathrm{E}\end{array}$ & $75.9,31.2,5.6$ & & S. Eberhard on 7 August 1998 \\
\hline
\end{tabular}




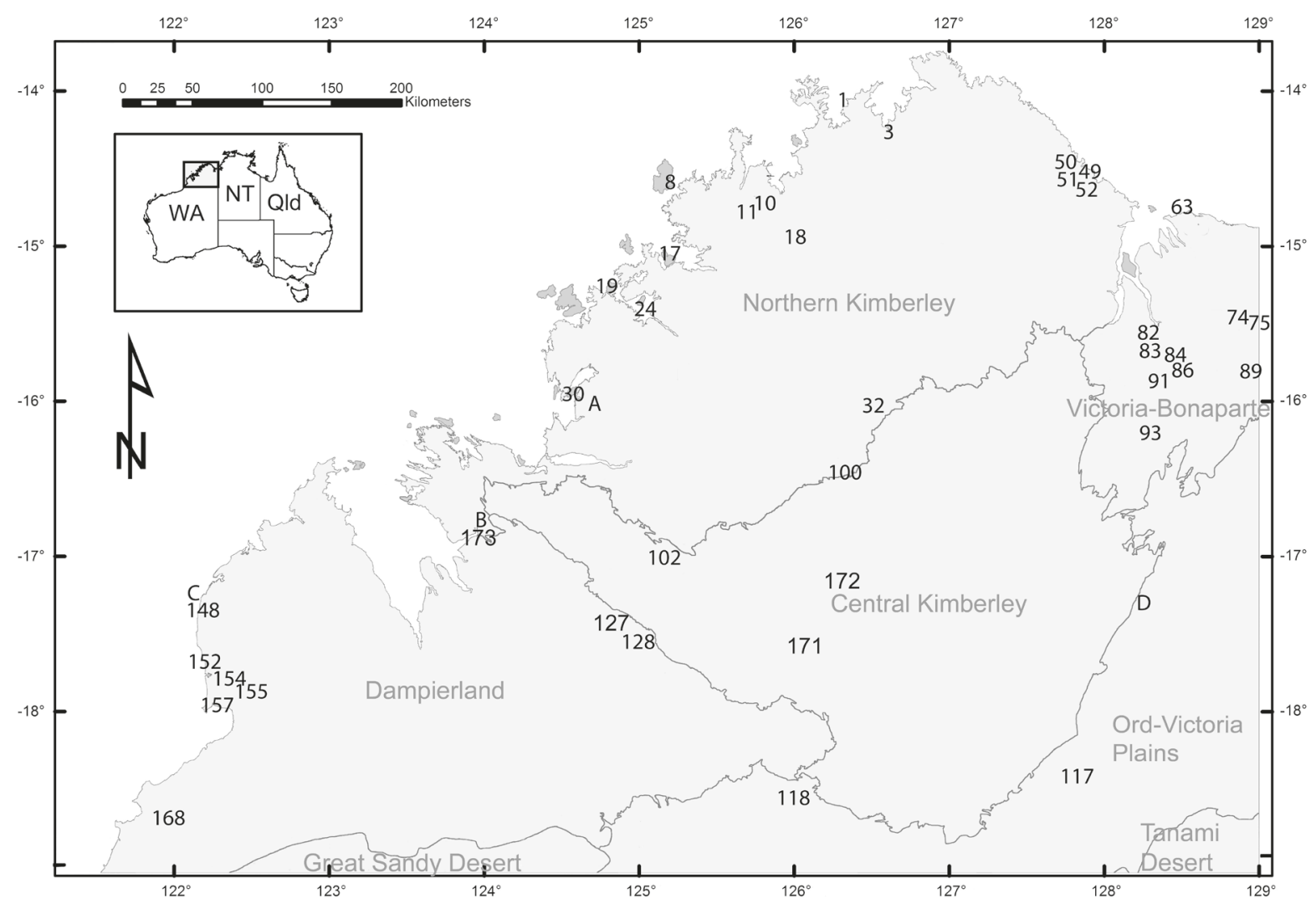

FIGURE 1 The Kimberley, showing the boundaries of its five biogeographic regions ('bioregions'), and the 40 sites where S. saccolaimus sequences were detected (Appendix 4). Museum voucher specimens exist from four of these 'numbered' sites as well as four others (marked as A to D in Table 1). Relevant Australian States are labelled: WA (Western Australia), NT (Northern Territory) and Qld (Queensland).

in sedimentary basins on its eastern, south-eastern and southern sides. The most mesic, the Northern Kimberley, encompasses $82,540 \mathrm{~km}^{2}$ of sub-humid near-coastal as well as inland landscapes. The most arid, Dampierland, comprises $88,120 \mathrm{~km}^{2}$ of semi-arid nearcoastal and inland landscapes, mostly plains, and forms the north-western margin of the Canning Basin. The rest of the Canning Basin is occupied by the Great Sandy Desert.

Average annual rainfall ranges from $1,500 \mathrm{~mm}$ in the north-west to $400 \mathrm{~mm}$ in the south where it is locally unreliable, while average temperatures range from a daily maximum of $32.8^{\circ} \mathrm{C}$ in January to a night time minimum of $12^{\circ} \mathrm{C}$ in July. Nearly all rain falls during the 4 to 5 months of the 'wet' (November to March), the season of high humidity. The Kimberley Craton is drained by seasonally active river systems fringed by tall trees that form riparian forests or woodlands, and permanent pools are common. Its landscapes support savannas, tree steppes, woodlands and open forests. They include undulating hill country with broad valleys and rugged boulder country associated with extensive basalt, quartz sandstone and limestone karst uplands, ranges and plateaus dissected by gorges.
Two compositionally distinct zoophagic bat ensembles occur in the Kimberley. One occupies landward environments and comprises 19 species; the other occupies mangroves and comprises 16 species. Their deterministic compositional structure has been displayed in terms of acoustic parameters, foraging strategy and foraging microhabitat (McKenzie and Bullen 2012: Fig. 4).

\section{EXISTING SPECIMENS FROM THE KIMBERLEY}

We reexamined the WA Museum's Saccolaimus collection in search of adults with an 'outside canine width' of less than $5.7 \mathrm{~mm}$. We also recorded dorsal and ventral fur for overall colour, flecks, speckles or spots, and checked for bare areas on the rump.

\section{ACOUSTIC SURVEY}

Between 1987 and 2017, we sampled 173 sites scattered across the Kimberley using bat detectors placed at ground-level with microphones orientated nearvertically upwards to minimise echoes. The recording equipment improved during the sampling program. For the first 73 sites we used an Anabat II bat detector coupled to a Sony Walkman WMD6C cassette recorder or, after 2003, a Sony Walkman mono minidisc recorder 
(128 kHz sampling rate) or, after 2010, an Olympus LS10 digital recorder (see McKenzie et al. 2012). In all cases the detector's output was saved in pulse code modulation (PCM) wave format. From 2012 onwards, we used a Wildlife Acoustics SM2BAT full-spectrum ultrasound recorder (384 $\mathrm{kHz}$ sampling rate) coupled with an omni-directional SMX-US ultrasonic microphone to sample another 100 sites. Taped to the tip of a stake, the microphone was about $1.5 \mathrm{~m}$ above the ground and several metres from obstructions. The SM2 recorder was pre-programmed to switch on at late dusk and record until dawn. Kaleidoscope (Version 2.3.0, Wildlife Acoustics 2015) was used to extract bat echolocation sequences from the SM2 recordings, and save them as individual sound files in PCM wave format. Sites were sampled for at least one night each with the SM2, but at least two nights each with the Anabat systems, supplemented with mist nets and/or spotlight collecting at 78 of the (mostly) pre-2012 sites (Animal Ethics approvals: DEC AEC 2007/03, 2010/21).

Rather than randomly arrayed, the recording sites were strategically selected to sample the study area's main ecosystems and provide geographical coverage. Most were in or within $0.2 \mathrm{~km}$ of savanna woodlands (146 sites), rainforest (26), mangroves (47), and/or riparian zones (69). They were in, or within $0.2 \mathrm{~km}$ of, plains country (59), undulating hill country (62) and/or rugged range country with crevices and caves (71).

COOL EDIT 2000, now 'Adobe Audition 2' (Adobe Systems, USA), was used to display each echolocation sequence in spectral view and measure pulse parameters such as peak frequency $\left(F_{\text {peak }}\right)$ and fineness-of-tuning $(Q)$, as described in McKenzie and Bullen (2012). $Q$ is the width of the frequency band $6 \mathrm{~dB}$ below peak, taken from the Fast Fourier Transform (i.e. $\left.Q_{-\sigma d B}\right)$. $Q$-values were corrected to allow for the higher resolution offered by the SM2's full-spectrum recordings compared to the frequency-divided (/16) output from Anabat detectors, then standardised at $Q_{\mathrm{SM} 2} / 3.0$ for calculation purposes. The correction factor was derived empirically using field-recorded sequences emitted by species whose search mode pulse frequencies straddle the relevant 17 to $24 \mathrm{kHz}$ frequency band, i.e. S. flaviventris and Taphozous georgianus (Appendix 1).

Sequences were identified to species using the reference echolocation library and procedure described in McKenzie and Bullen (2012). This library comprises PCM wave file recordings of known free-flying individuals (cyalume-tagged or shot). It comprises 26 species (all species known from the Kimberley) and 248 sequences with an average of 9.5 sequences per species (s.d. =6), and 2,322 individual pulses at an average of 89 pulses per species (s.d. $=46$ ). Thus, $F_{\text {peak }}$ and $Q$ values were determined for several of the search-mode pulses comprising a sequence, along with pulse repetition-rate (to confirm that the bat was in search mode), shape, duration $(D u r)$, and overall slope $\left(\left(F_{\max }-F_{\text {characteristic }}\right) /\right.$ duration). $F_{\text {peak }}$ is equivalent to $F_{\text {peakc }}$ when Anabat wave files were used, and to ' $0.94 F_{\text {characteristic }}+1.57$ ' $\left(\mathrm{R}^{2}=0.95\right.$, $\mathrm{n}=18$ ) when Anabat-ZCAIM files (see Corben 2004) were used, i.e. for the three Northern Territory reference sequences described below. Because its component variables are independent of the hardware, the Slope equation should yield comparable values irrespective of whether recordings are processed using Anabat-ZCAIM or SM2-wave file formats, but we are yet to derive an algorithm yielding reliable Slope values from Anabat wave files.

The echolocation library comprises a scatterplot of pulse $F_{\text {peakC }}$ versus $Q$, as well as a table summarising other pulse and sequence attribute values for species in free-flight, such as pulse duration and repetition rate.

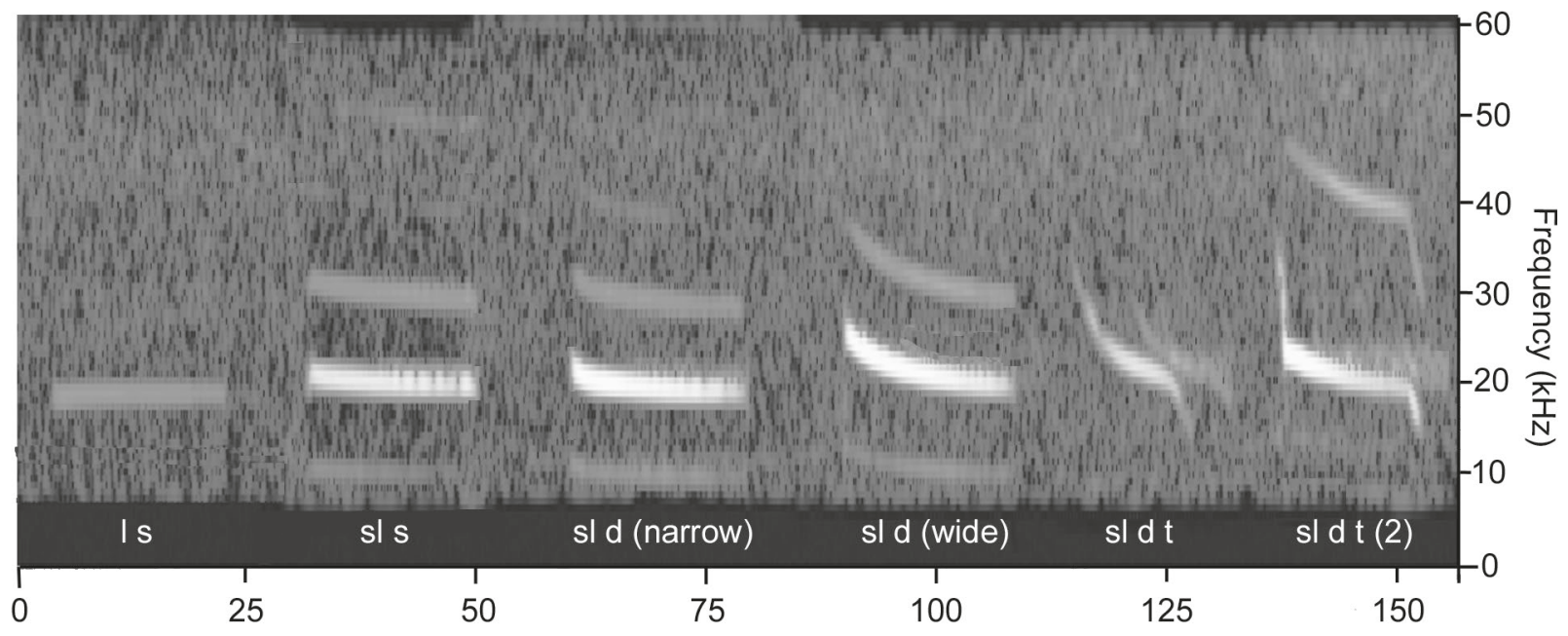

Time (ms)

FIGURE 2 Spectral view of typical search-mode pulses by Kimberley $S$. saccolaimus, displaying different search mode pulse shapes. From left to right: level straight ('I s', $F_{\text {peak }} 18.7 \mathrm{kHz}$, duration $19 \mathrm{~ms}$, Slope 0.00 $\mathrm{kHz} \mathrm{ms}^{-1}$ ), slant straight ('sl s', 19.9, 16, 0.08), narrow bandwidth slant dished ('sl d', 19.4, 18, 0.12), wide bandwidth slant dished ('sl d', 20.7, 15, 0.29), slant dished with tail ('sl d t', 21.3, 15, 0.51), and a second version of 'sl d t' (21.1, 14, 0.28). 
In diagnosing pulse sequences, we ignored pulses that did not meet the clarity, duration, shape and sequence repetition rate criteria used in compiling the library. For instance, the echo that partially overlies pulse ' $\mathrm{sl} \mathrm{d} \mathrm{t}$ ' in Figure 2 can induce errors such as low Q estimates and/or exaggerated duration values. Unknown pulses that plotted on the periphery of a pulse cluster in the library scatterplot were identified only if they were in continuous sequence with pulses that fell within the cluster. Unknown pulses that plotted in an area of overlap between two species were not identified unless they were in continuous sequence with at least three pulses that fell in an area of the cluster that was outside of the overlap.

S. saccolaimus was not included in our 2012 echolocation library for the Kimberley. At that time, search mode echolocation sequences were assigned to $S$. flaviventris if they included undistorted pulses at $14<F_{\text {peakc }}<21 \mathrm{kHz}$ with $Q>11$ (strongest harmonic 'frequency at peak cycles' and 'fineness-of-tuning', respectively, from Anabat recordings) that were $>17 \mathrm{~ms}$ long and emitted at an integer fraction of circa $7 \mathrm{~Hz}$ (McKenzie and Bullen 2012: i.e. c. $3.7 \mathrm{~Hz}$ if emitted every second wing beat, c. $2.3 \mathrm{~Hz}$ if every third, c. $1.75 \mathrm{~Hz}$ if every fourth, etc). Oddly, some sequences were comprised entirely of pulses at $>19 \mathrm{kHz}$. Also, these pulses had unexpectedly high $Q$-values, given the inverse relationship between $F_{\text {peakc }}$ and $Q$ shown by emballonurid bats (McKenzie and Bullen 2012). In addition, the detectable bandwidth of the strongest harmonic in these odd pulses was surprisingly narrow for field recordings of free-flying $S$. flaviventris near the high end of its search mode frequency range, and resembled the pulses in two of the Northern Territory S. saccolaimus sequences illustrated by Milne et al. (2009: Figs 4b-c).

Consequently, we have reassigned Kimberley sequences to $S$. saccolaimus if they match, or are in continuous sequence with pulse-series that match, (1) the Kimberley reference sequence (by specimen M49194, flying in open air above tree canopy) and/ or (2) the descriptors for sequence-types (b) and (c) in Fig. 4 of Milne et al. (2009). Their study identified three different search mode sequences from AnabatZCAIM reference recordings of Northern Territory $S$. saccolaimus, each emitted in a different environmental setting. Within each sequence-type, the individual pulses were of similar shape. Three distinct shapes can be discerned, and are among those illustrated in Figure 2:

1. Narrow bandwidth slant dished ('sl d') pulses, emitted in open air very high above tree canopy (Milne's type (b), Northern Territory Museum specimen U4080),

2. a wide bandwidth version of 'sl d', emitted 'just above the tree canopy' (Milne's type (c), NTM U5231), and

3. slant dished with a tail ('sl d t') pulses, emitted $\sim 2 m$ above the ground' (Milne's type (a), NTM U4079).
In terms of 'minimum frequency and characteristic call frequency', Milne et al. (2009) concluded that all three types were different from pulse sequences by its syntopic acoustic neighbour, S. flaviventris, but having lumped the three types together for the statistical comparison, found '...the call signature could not be reliably used to distinguish' these two species (p. 506).

Using 'species+pulse shape' as the classification variable (see below), Canonical Discriminant Analysis (STATISTICA version 6) was used to test whether S. flaviventris, S. saccolaimus and C. jobensis echolocation sequences could be separated in terms of the pulse sequence attributes listed earlier. The data points were the averaged ultrasound attributes of each sequence in the reference library, the type (b) and (c) reference sequences from the Northern Territory, and the Kimberley sequences that we assigned to $S$. saccolaimus. Sequences averaging $>21.1 \mathrm{kHz}$ were excluded to avoid approach-mode pulses. Because we do not have an algorithm yielding reliable Slope values from Anabat wave files, the 98 data points (57\%) derived from these recordings could not be included in the discriminant function analysis.

\section{RESULTS}

\section{EXISTING KIMBERLEY SPECIMENS}

Our search of the WA Museum collection revealed three additional specimens of $S$. saccolaimus from Kimberley localities (M44078, M24045 and M22535), making a total of eight (Table 1), all collected between 1977 and 2006. Three of the eight specimens came from sites that we subsequently sampled using ultrasound detectors and, fortuitously, one (M49194) was shot while its echolocation pulses were being recorded.

In terms of adult forearm length and body weight, available Kimberley specimens are within the ranges reported for Northern Territory specimens: $40.7 \mathrm{~g}$ $($ S.D. $=2.6, \mathrm{~N}=5)$ and $73.2 \mathrm{~mm}(1.9,7)$ from Table 1, compared to $47.2 \mathrm{~g}(11.6,3)$ and $74.9 \mathrm{~mm}(2.1,22)$ from Milne et al. (2009), respectively. Also consistent with Northern Territory specimens, none of the eight Kimberley specimens have naked rumps, and the fur on their dorsal surfaces is very dark brown. Two have white hairs in one to four diffuse, mid-dorsal patches (M26078 and M22535). M26078 also has a few individual white hairs elsewhere on its back, and M49194 has just two such hairs but no patches. Ventral surfaces are covered with uniform white or cream fur in all eight cases.

\section{ECHOLOCATION DETECTIONS IN THE KIMBERLEY}

Pulses comprising the Northern Territory and Kimberley reference sequences that were recorded from $S$. saccolaimus flying in open air space ('above the tree canopy') did not show significant differences in $F_{\text {peak }}$, Shape, Slope or Dur (Table 2). Two additional pulse shapes illustrated in Figure 2 (' $1 \mathrm{~s}$ ' and 'sl s') were accepted as $S$. saccolaimus because they were 
in-sequence with pulse shapes present in the Northern Territory and/or Kimberley reference sequences ('sl d' and 'sl d t').

The averaged spectral statistics of the search mode echolocation sequences used as data points for the discriminant function analysis (DFA) are displayed in Table 3. Shape (Figure 2) was used as the grouping variable. Because the frequency-, Slope- and $Q$-values of sequences comprising pulse shapes ' $1 \mathrm{~s}$ ' and 'sl s', as well as 'sl d' and 'sl d t', were not statistically separable for either $C$. jobensis or $S$. saccolaimus (i.e. the standard deviations overlapped the averages), these shape categories were merged in the DFA. Furthermore, since only a single search mode sequence comprising 'ss t' pulses was observed (by $C$. jobensis), it could not be included in the analysis as a separate group, so was added to C. jobensis's 'sl d t $+\mathrm{sl} d$ ' group for the analysis. Thus, we pooled the $C$. jobensis sequences into two 'observed' groups (' $1 \mathrm{~s}+\mathrm{sl}$ s' and 'sl d + sl d t + ss t'), $S$. saccolaimus sequences into two 'observed' groups ('l s' + 'sl s' and 'sl d + sl d t'), but left $S$. flaviventris sequences as three groups (' $1 \mathrm{~s}$ ', 'sl s' and 'sl d').

Discriminant analysis of these sequences showed that the three bat species were distinct in terms of the spectral attributes assessed. The first discriminant function $\left[\mathrm{Fn}(1)=-1.35 F_{\text {peak }}+0.35\right.$ Slope $\left.-1.38 Q+0.51 D u r\right]$

TABLE 2 Comparison of echolocation pulses comprising reference sequences recorded from Northern Territory (NTM U4080) and Kimberley (WAM49194) S. saccolaimus: Average (s.d., number of pulses); d.f. = 16, 2-tailed test.

\begin{tabular}{lllll} 
& $F_{\text {peakc }}(\mathrm{kHz})$ & Slope $\left(\mathrm{kHz} \mathrm{ms}^{-1}\right)$ & Dur $(\mathrm{ms})$ & Shape \\
\hline M49194 & $20.7(0.2,9)$ & $0.08(0.03,9)$ & $15.1(0.8,9)$ & sl d \\
U4080 & $21.0(0.5,9)$ & $0.09(0.02,9)$ & $15.1(0.7,9)$ & sl d \\
Student- $t$ (p.) & $-1.55(0.14)$ & $-0.70(0.49)$ & $0.00(1.00)$ & \\
\hline
\end{tabular}

TABLE 3 Averaged spectral statistics of the strongest harmonic in search mode echolocation sequences: Mean (s.d.) of sequences in terms of the peak frequencies (avF), slopes (avSlope), av $Q$ and durations (avDur) of their component pulses. Chaerephon jobensis (Cj), S. saccolaimus (SC), S. flaviventris (Sf). Pulse shape categories: level straight (| s), slant straight (s|s), slant dished $(s \mid d)$, slant dished with tail $(s \mid d t)$ and s-shaped with tail (ss t). Total numbers, mean (s.d.) of pulses measured in each shape category are also provided, along with number of sequences and different localities represented. Kimberley bioregions are Dampierland (DL), Northern Kimberley (NK), Central Kimberley (CK), Ord-Victoria Plains (OVP) and Victoria-Bonaparte (VB). Northern Territory (NT) bioregions are Gulf Coast (GUC) and Top End Coast (TEC).

\begin{tabular}{|c|c|c|c|c|c|c|c|c|c|}
\hline & Shape & av $F$ & avSlope & $\operatorname{av} 0$ & avDur & Seq. & Pulses & Localities & Bioregions \\
\hline \multirow{5}{*}{$C j$} & ls & $14.7(0.6)$ & $0.02(0.01)$ & $11.1(0.1)$ & $16.2(0.2)$ & 2 & 4 & 2 & $\mathrm{NK}, \mathrm{CK}$ \\
\hline & sl s & $14.6(0.6)$ & $0.03(0.01)$ & $11.4(0.9)$ & $15.3(0.8)$ & 3 & $13,4.3(2.1)$ & 3 & NK, DL \\
\hline & $\mathrm{sld}$ & $18.4(1.8)$ & $0.43(0.18)$ & $8.4(1.8)$ & $13.0(1.9)$ & 7 & $20,2.9(2.6)$ & 4 & NK, VB, CK, DL \\
\hline & $\mathrm{sld} \mathrm{t}$ & $17.9(1.5)$ & $0.36(0.16)$ & $9.9(1.2)$ & $14.6(1.3)$ & 13 & $100,7.7(5.4)$ & 6 & NK, VB, CK, DL \\
\hline & ss t & 20.7 & 0.95 & 6.2 & 10.0 & 1 & 9 & 1 & VB \\
\hline \multirow{4}{*}{$S c$} & 1s & $19.6(0.5)$ & $0.05(0.02)$ & $16.1(0.3)$ & $18.1(0.7)$ & 3 & $22,7.3(3.2)$ & 2 & NK, DL \\
\hline & $\mathrm{sl} \mathrm{s}$ & $20.0(0.7)$ & $0.14(0.08)$ & $15.1(1.2)$ & $17.4(3.1)$ & 5 & $16,3.2(3.3)$ & 4 & NK, DL \\
\hline & sld & $20.4(0.4)$ & $0.28(0.09)$ & $12.9(1.2)$ & $15.0(2.6)$ & 16 & $83,5.2(4.1)$ & 13 & $\begin{array}{l}\text { NK, VB, CK, DL and GUC. } \\
\text { TEC in the NT }\end{array}$ \\
\hline & $\mathrm{sl} \mathrm{d} \mathrm{t}$ & $20.4(0.5)$ & $0.31(0.04)$ & $13.0(1.1)$ & $14.3(1.2)$ & 4 & $9,2.3(1.9)$ & 3 & NK, VB, DL \\
\hline \multirow{3}{*}{$S f$} & ls & $16.7(1.0)$ & $0.05(0.02)$ & $13.0(0.3)$ & $17.8(1.0)$ & 6 & $23,3.8(4.6)$ & 4 & NK, VB, CK, DL \\
\hline & $\mathrm{sl} \mathrm{s}$ & $17.7(1.0)$ & $0.10(0.02)$ & $13.1(0.8)$ & $18.5(1.8)$ & 4 & $16,4.0(2.4)$ & 3 & NK, VB, DL \\
\hline & $\mathrm{sld}$ & $19.6(1.1)$ & $0.33(0.16)$ & $11.5(2.2)$ & $14.2(4.2)$ & 13 & $40,3.1(2.2)$ & 11 & NK, CK, OVP, DL \\
\hline
\end{tabular}


TABLE 4 Pulse fineness-of-tuning $(Q)$ statistics according to $F_{\text {peak. }}$ Comprises $Q_{\text {Anabat }}$ and $Q_{\mathrm{Sm} 2} / 3.0$ values. Average $Q$ (s.d.), 'rn' = number of reference pulses, ' $r N$ ' = number of reference sequences, ' $n$ ' = number of pulses, $' N '$ = number of sequences, 'p/s' = average number of pulses per sequence (s.d.).

\begin{tabular}{|c|c|c|c|c|c|c|c|c|c|c|}
\hline & $F_{\text {peak }}(\mathrm{Khz})$ & $<16$ & 16 & 17 & 18 & 19 & 20 & 21 & 22 & Totals \\
\hline \multirow{3}{*}{$C j$} & $Q$ & $11.1(1.0)$ & $11.4(1.5)$ & $10.5(1.8)$ & $9.4(1.9)$ & $8.7(1.6)$ & $7.1(1.4)$ & $7.1(1.3)$ & & \\
\hline & $\mathrm{rn}, \mathrm{rN}$ & 37,9 & 36,12 & 59,20 & 74,22 & 59,22 & 43,18 & 10,8 & & 318,42 \\
\hline & $\mathrm{p} / \mathrm{s}$ & & & & & & & & & $7.6(6.0)$ \\
\hline \multirow{3}{*}{ Sf } & $Q$ & $13.6(1.2)$ & $13.1(0.9)$ & $13.5(1.2)$ & $13.6(1.8)$ & $12.2(2.5)$ & $9.4(1.2)$ & $8.9(1.8)$ & & \\
\hline & $\mathrm{rn}, \mathrm{rN}$ & 11,8 & 51,10 & 66,17 & 55,17 & 59,16 & 29,13 & 4,4 & & 275,48 \\
\hline & $\mathrm{p} / \mathrm{s}$ & & & & & & & & & $5.8(6.7)$ \\
\hline \multirow{4}{*}{$S c$} & $Q$ & & & & $16.4(1.9)$ & $14.8(1.6)$ & $13.1(1.9)$ & $11.2(2.1)$ & $8.3(1.4)$ & \\
\hline & $\mathrm{n}, \mathrm{N}$ & & & & 6,2 & 93,15 & 91,21 & 51,10 & 13,3 & 254,36 \\
\hline & $\mathrm{rn}, \mathrm{rN}$ & & & & 0,0 & 4,1 & 20,3 & 13,2 & 0,0 & 37,3 \\
\hline & $\mathrm{p} / \mathrm{s}$ & & & & & & & & & $6.4(6.6)$ \\
\hline
\end{tabular}

had a canonical correlation coefficient of 0.96 and accounted for $90 \%$ of the observed variance in the echolocation data (p. $<0.00001)$. The second function $\left[\mathrm{Fn}(1)=-0.18 F_{\text {peak }}+0.85\right.$ Slope $-1.06 Q+0.08 D$ ur $]$ had a canonical correlation coefficient of 0.71 , accounted for $9 \%$ of the remaining variation, and was also significant (p. $<0.00001)$. The coefficients in these functions have been standardised; they reveal the relative contributions of the spectral attributes in separating species and their shape groups.

Unstandardised coefficients were used to generate the discriminant scatterplot (Figure 3). Only one of the 77 sequences was classified to the wrong species (posterior probability assignments are tabulated in Appendix 2). An 'assigned' sequence of five $14 \mathrm{~ms}$ 'slant-dished' pulses ( $\mathrm{Sc} 2 \mathrm{125}$ ), it was originally assigned to $S$. saccolaimus, but classified to $S$. flaviventris (posterior probability $=0.62$ ) rather than $S$. saccolaimus $(0.37)$ because its average $Q$ of 10.9 was slightly low for $S$. saccolaimus at $20.6 \mathrm{kHz}$ (see Table 4, above). The three reference $S$. saccolaimus sequences were correctly classified: M49194 (ScrK, posterior probability 0.91), U4080 (ScrNToc, 0.92) and U5231 (ScrNTac, 0.73). We conclude that Kimberley $S$. saccolaimus sequences are consistent with their Northern Territory counterparts but distinct from $S$. flaviventris and $C$. jobensis.

The coefficients of the standardised discriminant functions listed above reveal that two of the four variables contributed most to species separation $\left(F_{\text {peak }}\right.$ and $\left.Q\right)$. To widen the comparison, characterise the differences and simplify species recognition, we tabulated these two variables for the individual search mode echolocation pulses comprising (1) S. flaviventris and $C$. jobensis reference sequences from the Kimberley and elsewhere in tropical Western Australia, (2) the Kimberley sequences that were classified as $S$. saccolaimus by the DFA, and (3) S. saccolaimus reference sequences from the Northern Territory and Kimberley (Table 4).

The differences in $Q$ were significant ( $\mathrm{p} .<0.05$ ) because the standard deviation did not overlap the mean of another species in any frequency band (Table 4). In search-mode, $S$. saccolaimus uses the upper half of the frequency band occupied by syntopic $C$. jobensis and $S$. flaviventris (Table 4), but at these frequencies (between 18.7 and $21.1 \mathrm{kHz}$ ), S. saccolaimus pulses are more finely tuned (i.e. have higher $Q$, Student- $t=-4.620$, p. $<0.0001$, d.f. $=39,2$-tailed test) and have lower Slope values $(t=-3.709$, p. $<0.0001,31$ (Table 3$))$. Appendix 3 provides relevant statistics for the pulse-shape categories of Kimberley $S$. saccolaimus, $S$. flaviventris and $C$. jobensis.

With an average $F_{\text {peak }}$ of $23.1 \mathrm{kHz}, S$. saccolaimus sequences from a Queensland population (Table 5) were $2.8 \mathrm{kHz}$ higher than their Northern Territory/Kimberley counterparts, but consistent in all other characters assessed.

Overall, echolocation sequences referrable to $S$. saccolaimus were recorded at 40 (Figure 1, Appendix 4) of the 173 Kimberley sites where ultrasound recorders were deployed. The recordings confirm that it occurs throughout all five Kimberley bioregions (Table 3), and forages over all major ecosystems, both subhumid and semi-arid. Sequences were recorded from tropical woodlands and savannas on rugged sandstone and limestone uplands, ranges and gorges, as well as Carson Volcanics hill country, paperbark woodland associated with coastal sand dunes, mangroves, pindan on sandplains, and riparian forests. 
TABLE 5 Search-mode echolocation sequence statistics of Queensland (Qld) S. saccolaimus (Sc) derived from the strongest harmonic of free-flying pulse sequences (mean (s.d.)). The first column is derived from faint background sequences in the Cairns roost recordings supplied by G. Ford - probably individuals flying in more open airspaces above the trees. The second column is from individuals recorded as they flew towards the microphone after emerging from a roost. These sequences were recorded using a Wildlife Acoustics EMTouch 'full wave' ultrasound recorder at a sampling rate of $250 \mathrm{kHz}$. Parameters are explained in Table 3. 'Shape' refers to the pulse's appearance in spectral view (see Figure 2).

\begin{tabular}{llll} 
& Old $S c$ & Old $S c$ & Total \\
\hline av $F_{\text {peak }}$ range & $21.3-22.8$ & $23.8-24.7$ & $23.1(1.1)$ \\
$\operatorname{av} F_{\text {peak }}(\mathrm{kHz})$ & $22.1(0.4)$ & $24.2(0.3)$ & $16.1(2.4)$ \\
$\operatorname{avDur}(\mathrm{ms})$ & $17.9(1.1)$ & $14.1(1.4)$ & $0.09(0.03)$ \\
avSlope $\left(\mathrm{kHz} \mathrm{ms}^{-1}\right)$ & $0.07(0.01)$ & $0.12(0.01)$ & 1 \\
Shape & $\mathrm{sl} \mathrm{s}, \mathrm{sl} \mathrm{d}, \mathrm{sl} \mathrm{d} \mathrm{t}$ & $\mathrm{sl} \mathrm{d}, \mathrm{sl} \mathrm{d} \mathrm{t}$ & 17 \\
locations & 1 & 1 & 83 \\
sequences & 9 & 8 & 52 \\
pulses & 31 & $4.7(2.1)$ & \\
pulses per sequence & $5.3(2.5)$ & & 17 \\
\hline
\end{tabular}

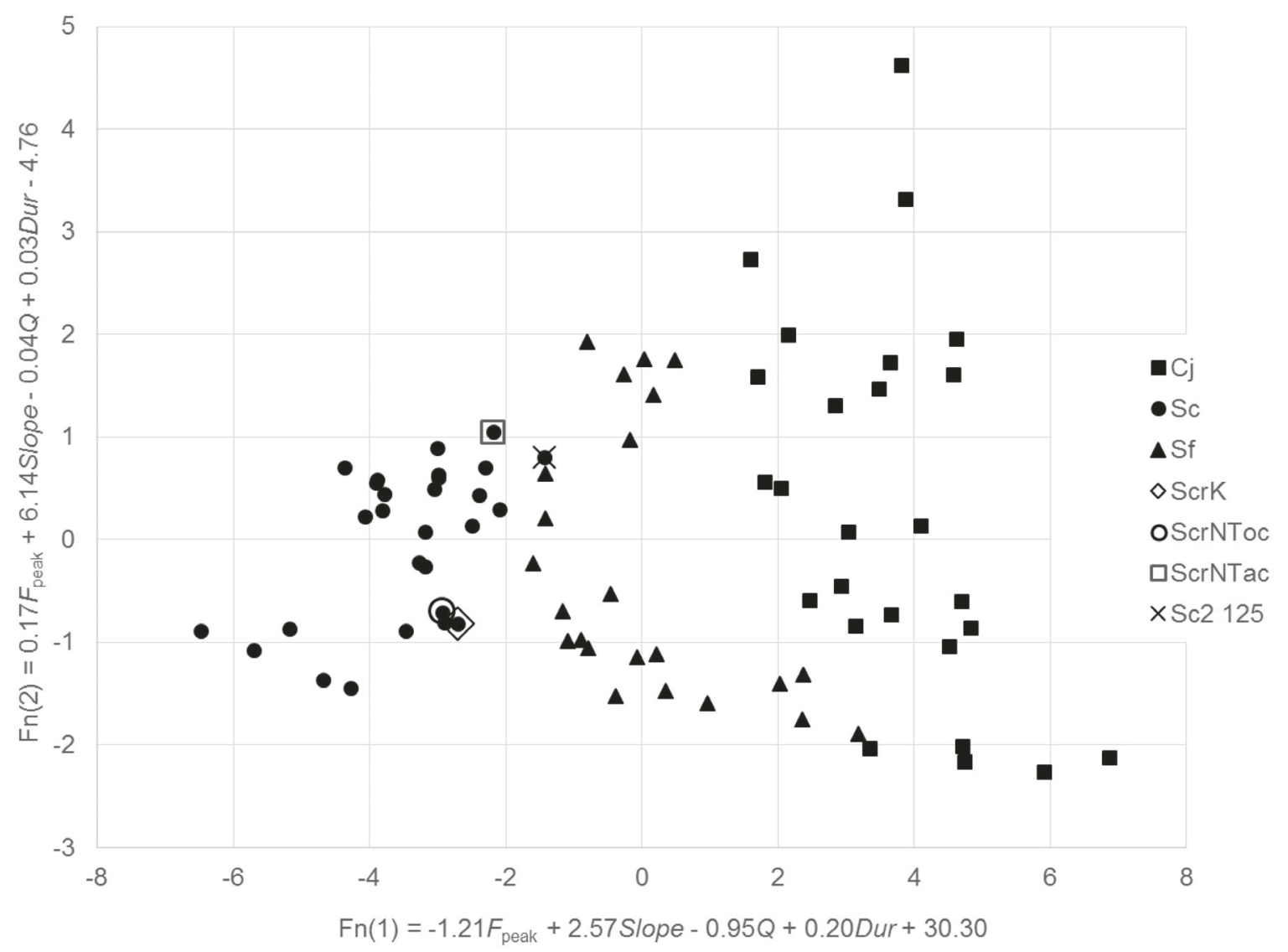

FIGURE 3 Standard DFA scatterplot of unstandardised canonical coordinates for sequences. Fn(1) Chi-square = 230.6 (d.f. $=24$, p. $<0.00000)$, and Fn(2) Chi-square $=59.1(15,<0.00000)$. Cj (C. jobensis), (Sc) S. saccolaimus and (Sf) $S$. flaviventris. The three reference $S$. saccolaimus sequences are circled and the misclassified sequence point is crossed. 


\section{DISCUSSION}

Voucher specimens in Western Australian Museum collections confirm that two species of Saccolaimus were extant in the Kimberley at least until 2006: S. flaviventris and S. saccolaimus. Like their Northern Territory counterparts, the two Kimberley Saccolaimus are so similar externally that zoologists had treated them as a single species. A DNA-verified $S$. saccolaimus specimen was collected at $15^{\circ} 45^{\prime} \mathrm{S}, 129^{\circ} 10^{\prime} \mathrm{E}$ (Milne et al. 2009), only $20 \mathrm{~km}$ north-east of our detection site 89 (Figure 1). Given its mode flight speed is c. $8 \mathrm{~m} / \mathrm{s}(26 \mathrm{~km} / \mathrm{h})$ and the continuity in appropriate habitat, we surmise that the Kimberley population is continuous with the Northern Territory population. The eight $S$. saccolaimus specimens were collected from landward environments of three Kimberley bioregions: Northern Kimberley (4 locations), Dampierland (3) and Ord-Victoria Plains (1).

Our analysis of ultrasound recordings from the Kimberley confirm that both species persist there today. For pulses of the same shape ('sl d'), the search-mode parameters of the vouchered central Northern Territory and western Kimberley sequences showed no significant differences. In fact, most Kimberley sequences matched one of the three 'flight-space specific' search-mode sequence-types documented for Northern Territory S. saccolaimus by Milne et al. (2009, p. 504), and the discriminant function analysis classified these Northern Territory sequences to the same species as the Kimberley S. saccolaimus sequences (Figure 3). Furthermore, these Northern Territory and Kimberley sequences showed the same narrow bandwidth $(3.5 \mathrm{kHz}$, i.e. 18.7-22.2), in contrast to the wider bandwidth of $S$. flaviventris (6 kHz, i.e. 15-21) (Table 4).

The third Northern Territory reference sequence also showed a similar pulse shape ('sl d t') to some Kimberley sequences, although its pulses were shorter in duration (10 vs $13 \mathrm{~ms}$ ), and higher in frequency (22.9 vs $21.1 \mathrm{kHz}$ ), so we cannot exclude the possibility that this Northern Territory sequence is in transition to approach mode. Even so, in terms of these two spectral variables, this Northern Territory sequence is within two standard deviations of comparable sequences from the Kimberley (Appendix 3).

In combination, our detection of $S$. saccolaimus at 40 of the 173 sites sampled in the Kimberley, in all five Kimberley bioregions, and in both landward and mangrove communities (Figure 1 and Appendix 4), suggests that this species is widespread at the western end of its Australian range. We detected S. saccolaimus foraging over all major ecosystems in the Kimberley, both sub-humid and semi-arid. Its habitats in the Northern Territory and Queensland are known to be similarly diverse, including Eucalyptus miniata-E. tetradonta woodland (Milne et al. 2009) as well as mangroves, lowland tropical rainforest and littoral forest (Meutstege et al. 2014).

The echolocation signatures identified in this study will provide a quick, unambiguous basis for field survey of $S$. saccolaimus, without disrupting the normal activities of this vulnerable bat.

\section{ACKNOWLEDGEMENTS}

We thank A.A. Burbidge, P. Doughty, L.A. Gibson, M.H. McKenzie, R. O’Donnell, R.A. Palmer, T. Sonneman, A.N. Start and T. Vigilante for assisting with field sampling, the Balanggarra, Bardi-Jawi, Dambimangari, Mayala and Uunguu native title groups for access to country, and two anonymous referees for helpful comments on the manuscript. Greg Ford provided the $S$. saccolaimus reference recordings from Queensland, the Western Australian Museum provided access to their collections and Matthew Williams provided advice on DFA. Funding for the fieldwork was provided by the WA Department of Biodiversity, Conservation and Attractions, and the authors.

\section{REFERENCES}

Corben, C. (2004). Zero-crossing analysis for bat identification: an overview (pp. 95-107). In: Bingham, M.R., Kalko, E.K.V., Jones, G., Parsons, S. and Limpens, H.J.G.A. (eds), Bat Echolocation Research: Tools, Techniques and Analysis. Bat Conservation International: Austin, Texas.

DSEWPaC (2012). Interim biogeographic regionalisation for Australia (IBRA), Version 7 (Subregions) - States and Territories. Department of Sustainability, Environment, Water, Population and Communities, Canberra, Australia. Available at http://www.environment.gov.au/ topics/land/nationalreserve-system/science-maps-anddata/australias-bioregions-ibra.

McKenzie, N. L., and Bullen, R.D. (2012). An acoustic survey of zoophagic bats on islands in the Kimberley, Western Australia, including data on the echolocation ecology, organisation and habitat relationships of regional communities. Records of the Western Australian Museum Supplement 81: 67-108. doi: 10.18195/issn.0313$122 \mathrm{x} .81 .2012 .067-108$

Meutestege, R., Coles, R. and Spencer, H. (2014). Observations on the foraging and roosting behaviour of the bare-rumped sheathtail bat Saccolaimus saccolaimus in the Cape Tribulation region of Queensland, Australia. The Australasian Bat Society Newsletter, Number 42: 34.

Milne, D.J., Jackling, F.C., Sidhu, M. and Appleton, B.R. (2009). Shedding new light on old species identifications: morphological and genetic evidence suggest a need for conservation status review of the critically endangered bat, Saccolaimus saccolaimus. Wildlife Research $\mathbf{3 6}$ : 496-508.

T.S.S.C. (2016). Approved conservation advice for Saccolaimus saccolaimus nudicluniatus (bare-rumped sheath-tailed bat). Threatened Species Scientific Committee 7 December 2016. Department of the Environment and Energy, Canberra, Australia. Available from: http://www.environment.gov.au/biodiversity/ threatened/species/pubs/66889-conservationadvice-07122016.

Woinarski, J.C.Z., Burbidge, A.A. and Harrison, P.L. (2014). The action plan for Australian mammals 2012. CSIRO Publishing: Melbourne, Australia, xiii +1038 pp.

MANUSCRIPT RECEIVED 30 APRIL 2018; ACCEPTED 27 SEPTEMBER 2018. 


\section{ELECTRONIC APPENDICES}

1 Comparison of $Q_{-6 d B}$ values derived from Anabat and SM2BAT+ recordings of search mode echolocation sequences by S. flaviventris and T. georgianus.

2 Posterior probability matrix derived from the discriminant function analysis.

3 Statistics of the strongest harmonic in search-mode echolocation pulses according to shape.

4 Site location, habitat and bioclimatic attributes.

An electronic version of these appendices are available to download here: http://dx.doi.org/10.18195/issn.0312-3162.33(2).2018.135-144 